\title{
Hand injuries in a human caused by a South American porcupine (ouriço- cacheiro)
}

\section{Haddad Jr V (1), Vieira RB (1), Cortes CR (2)}

(1) Department of Dermatology, Botucatu Medical School, São Paulo State University (UNESP - Univ Estadual Paulista), Botucatu, São Paulo State, Brazil; (2) Gama Filho Medical School, Gama Filho University, Rio de Janeiro, Rio de Janeiro State, Brazil.

ABSTRACT: Human injuries caused by South American porcupines (in Portuguese, ouriço-cacheiro) are rare. This study reports severe hand injuries provoked by the body spines of the animal in a human and discusses the circumstances involved in the accident, with emphasis on environmental factors.

KEY WORDS: South American porcupine, hand injuries, body spines, Brazil.

CONFLICTS OF INTEREST: There is no conflict.

\section{CORRESPONDENCE TO:}

VIDAL HADDAD JUNIOR, Departamento de Dermatologia e Radioterapia, Faculdade de Medicina de Botucatu, Caixa Postal 557, Botucatu, SP, 18.618-000, Brasil. Phone/fax: +55 143882 4922. Email: haddadjr@fmb.unesp.br. 


\section{INTRODUCTION}

South American porcupines, or ouriços-cacheiros, are rodent mammals that belong to the family Erethizontidae, with at least eight known species distributed among three genera: Coendou, Sphiggurus and Chaetomys (1) (Figure 1). They are arboreal animals that stay attached to tree branches through their long and prehensile tail and rarely come down to the forest floor. They feed mainly on leaves and fruits (from which they extract water), have nocturnal habits and are not often viewed, which makes their habits little known (2).

The South American porcupines have no resemblance to hedgehogs or porcupines of Eurasia and Africa. However, they present a similar defense mechanism that consists of spines up to ten inches in length, originated from modified body hairs. They are mainly distributed on the body sides and back, and bristle when the animal feels threatened. Domestic dog attacks on hedgehogs are fairly common and usually the dog is injured by a large number of spines on its snout. Accidents in humans, however, are rare.

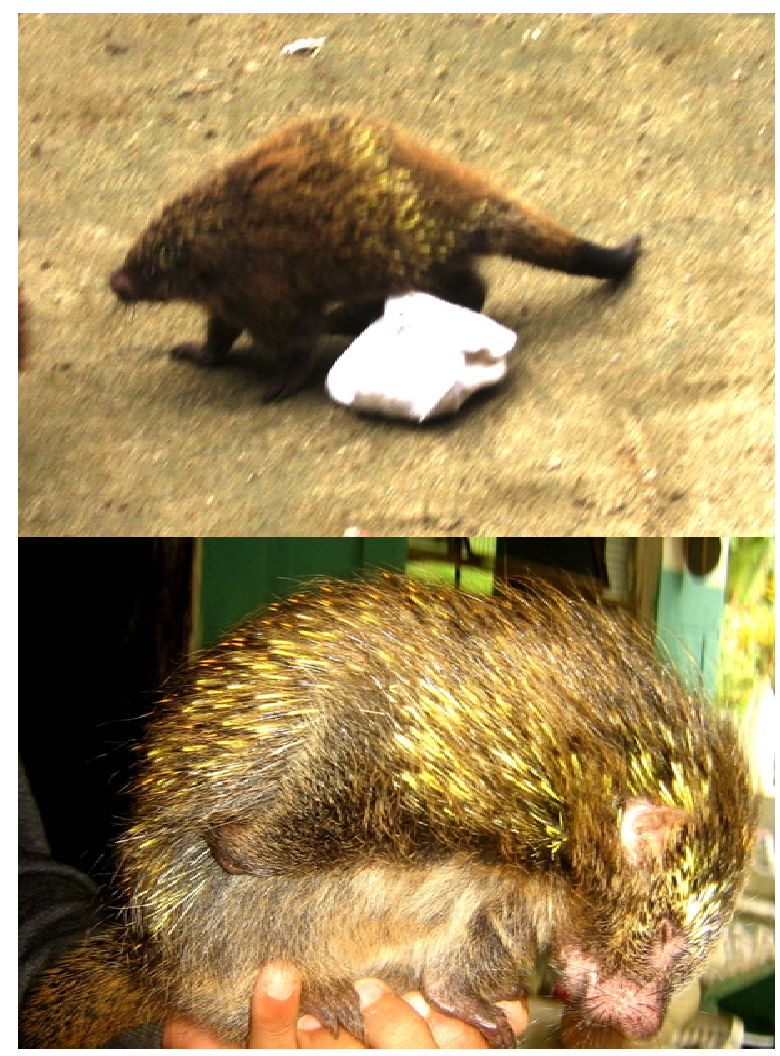

Figure 1. The South American porcupine or ouriço-cacheiro. Note the spines on the lateral and dorsal segments of the body. 


\section{CASE REPORT}

A 34-year old male was admitted to the emergency room of the municipal hospital Santa Casa de Ubatuba, in São Paulo state, Brazil, with numerous spines slicked in his right hand. The victim, a tourist, reported that he saw a porcupine in the woods near his vacation house and tried to capture it without knowing anything about the animal, even when it bristled and became more aggressive. While strongly holding the animal, several quills were released and embedded in the palm and fingers of his right hand, causing pain and psychomotor agitation (Figure 2). The spines were extracted with pliers after troncular anesthesia (Figure 3). After that, the patient was treated with cephalosporin for ten days and instructed to wash the area with soap and water three times a day. In the return consultation, after ten days, the injured area was completely recovered.

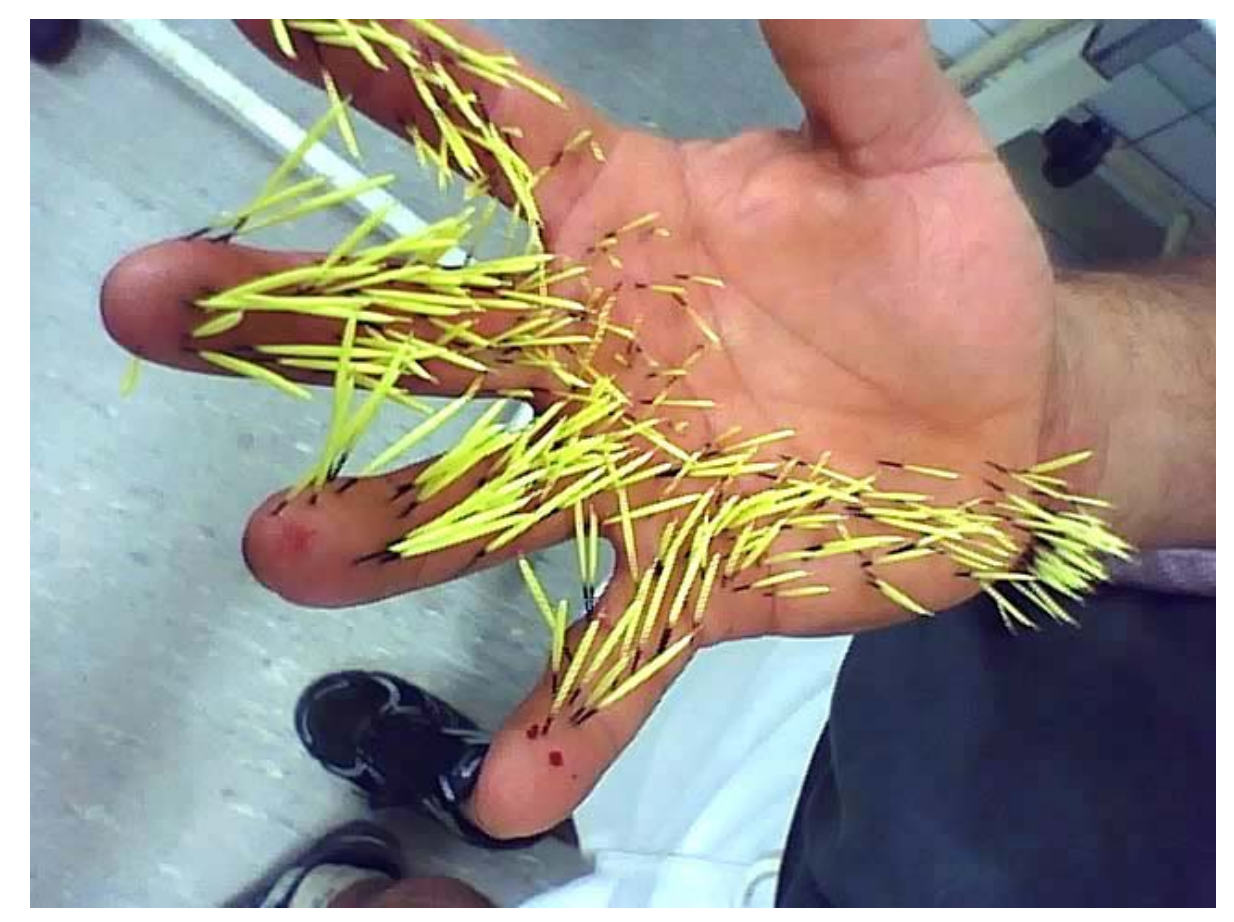

Figure 2. Injuries in the hand and fingers of the victim that attempted to hold the animal. 


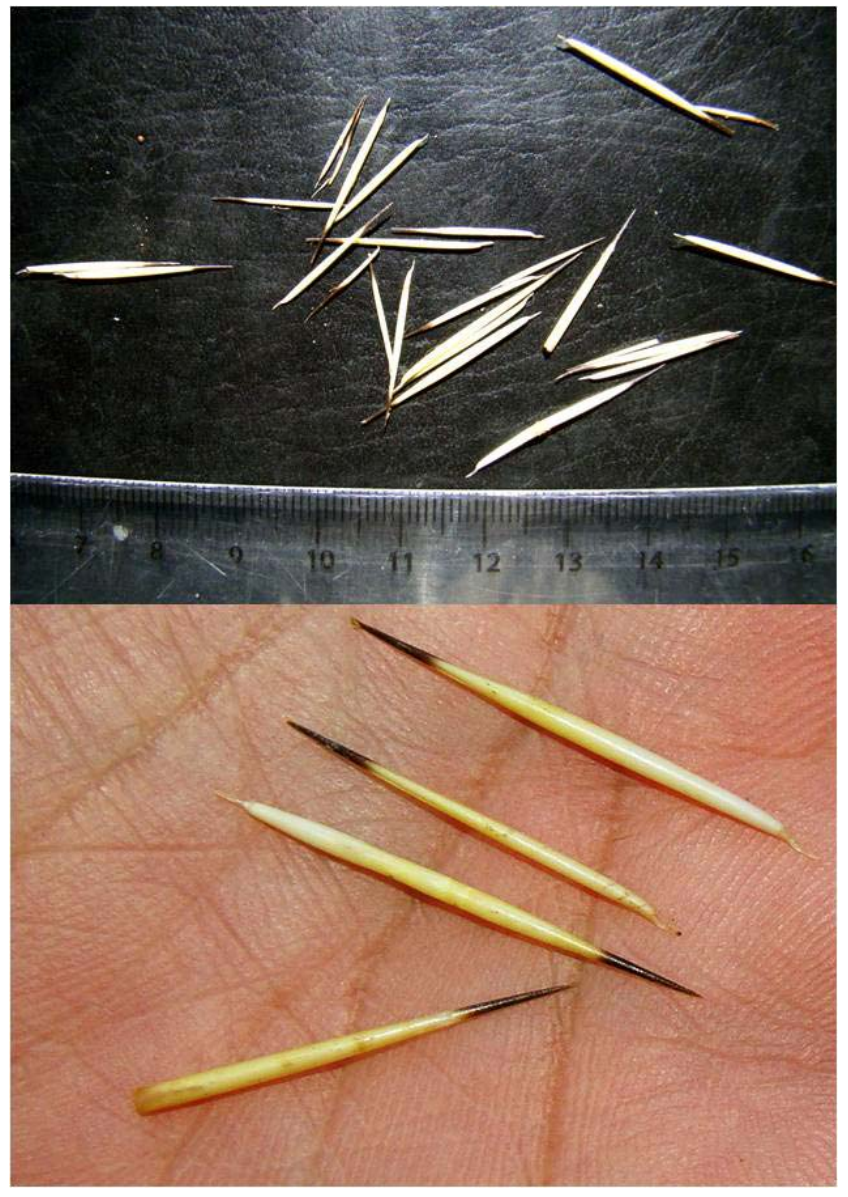

Figure 3. Details of body spines extracted from the patient.

\section{DISCUSSION}

The South American porcupines are shy animals that avoid contact with humans and present arboreal habits, rarely coming down to the ground. Accidents involving humans are therefore unlikely and motivate this communication. These animals have an effective defense mechanism based on their spines and are cognizant of the fact that inhabitants of the areas where they occur avoid them, which did not happen in the accident herein described due to the lack of knowledge of the victim. The Portuguese word cacheiro, resulting in the term ouriço-cacheiro, means "hiding" and the association is obvious.

Other interesting facts were the presence of severe pain, but only associated with the presence of quills, since it ceased completely after the removal of spines, even after the end of anesthesia.

Finally, it is worth recording the increasing incidence of accidents caused by wildlife in towns or their surroundings, which is due to a sum of factors, the most important being the increase of leisure activities in forest areas (Ubatuba city has most of its 
area covered by the Atlantic Forest) and the lack of knowledge of tourists regarding the fauna of these places (3). Accidents previously considered very rare or anecdotal are becoming increasingly more likely to happen, as this report shows.

\section{ACKNOWLEDGEMENTS}

We thank Marcelo Rebouças for the important information provided for this report.

\section{REFERENCES}

1. Prado R. Faltam informações, sobram lendas: verdades e mentiras sobre este roedor. Revista Terra da Gente Magazine, Terra da Gente Produções e Eventos. 2007;35:18-22.

2. Kuniy, AA, Rossi L, Gomes EPC. Análise do conteúdo estomacal e intestinal de dois espécimes de ouriço-preto (Chaetomys subspinosus) Olfers, 1818. Acta Biol Leopondensia. 2005;27(3):187-9.

3. Haddad Jr, V. Identificação de enfermidades agudas causadas por animais e plantas em ambientes rurais e litorâneos: auxílio à prática dermatológica. An Bras Dermatol. 2009;84(4);343-348. 